\title{
A RUPTURA DEMOCRÁTICA NA MODERNIDADE PERIFÉRICA: A GENERALIZAÇÃO DAS RELAÇÕES DE SUBINTEGRAÇÃO E SOBREINTEGRAÇÃO
}

\author{
Péricles Stehmann Nunes ${ }^{1}$ \\ José Francisco Dias da Costa Lyra ${ }^{2}$
}

Resumo: A pesquisa versa sobre as condições dos problemas do Estado Democrático de Direito frente aos países da modernidade periférica, especialmente, na experiência brasileira. Inicia-se, utilizando-se o método sistêmico-construtivista, analisando as condições negativas da realização do Estado Democrático de Direito na modernidade periférica, caraterizada pelas relações de "subintegração" e "sobreintegração", usando como embasamento teórico as obras de Marcelo Neves. A partir das análises, se conclui que há expectativas na realização da construção de um regime de bem-estar renovado, mesmo em tempos de crise democrática, visando que o Estado deve criar possibilidades político-jurídicas estruturais favoráveis para a promoção da inclusão social.

Palavras-chave: Estado Democrático; Modernidade periférica; Subintegraçãosobreintegração; Inclusão; Exclusão.

\section{THE DEMOCRATIC BREAKDOWN IN PERIPHERAL MODERNITY: THE GENERALIZATION OF UNDER-INTEGRATION AND OVER-INTEGRATION}

\begin{abstract}
The research deals with the conditions of the problems the Democratic State of Law in relation to the countries of peripheral modernity, especially in Brazilian experience. It begins by using systemic-constructivist method, analyzing the negative conditions of the realization the Democratic in the peripheral modernity, characterized by the relations of "subintegration" and "overintegration", using as theoretical of Marcelo Neves. From analyzes, it is concluded that are expectations in the realization of the construction of a renewed welfare regime, even in times of democratic crisis, aiming that the State should create favorable political-legal structural possibilities for the promotion of social inclusion.
\end{abstract}

Keywords: Democratic State; Peripheral modernity; Under-Integration-Over-Integration; Inclusion; Exclusion.

\footnotetext{
${ }^{1}$ Mestre em Direito pela Universidade Regional Integrada do Alto Uruguai e das Missões (URI) - Campus Santo Ângelo/RS. Especialista em Docência do Ensino Superior pela Universidade Católica Dom Bosco (UCDB). Membro do Grupo de Pesquisa Tutela dos Direitos e sua Efetividade, registrado no CNPq, vinculado ao Programa de Pós-Graduação em Direito - Mestrado e Doutorado da Universidade Regional Integrada do Alto Uruguai e das Missões (URI) - Campus Santo Ângelo/RS. E-mail: periclessn@gmail.com;

2 Doutor em Direito pela Universidade do Vale do Rio dos Sinos (UNISINOS). Mestre em Direito pela Universidade Regional do Noroeste do Estado do Rio Grande do Sul (UNIJUI). Professor do Curso de Doutorado e Mestrado em Direito da Universidade Regional Integrada do Alto Uruguai e das Missões (URI) Campus Santo Ângelo/RS. Também, leciona, na mesma instituição, as disciplinas de Direito Penal e Processo Penal. Professor de Direito Penal na Faculdade CNEC - Campus de Santo Ângelo. Líder do Grupo de Pesquisa Tutela dos Direitos e sua Efetividade, registrado no CNPq, vinculado ao Programa de Pós-Graduação em Direito - Mestrado e Doutorado da Universidade Regional Integrada do Alto Uruguai e das Missões (URI) - Campus Santo Ângelo/RS. Juiz de Direito no Estado do Rio Grande do Sul. E-mail: jfdclyra@tj.rs.gov.br.
} 


\section{INTRODUÇÃO}

As reflexões e análises constantes no presente artigo busca compreender os elementos e condições da ruptura democrática do Estado de Direito na sociedade complexa, sob o paradigma sistêmico de Luhmann, a fim de compreender os problemas que se referem ao conceito de acoplamento estrutural ligados à Constituição, em face dos processos que se delineiam no sentido da urgência de uma promoção de inclusão social.

Nesse cenário, consoante as obras de Marcelo Neves, será abordada a temática da alopoiese do sistema jurídico, em que corresponde a um problema da modernidade periférica e da sociedade mundial do presente, partindo da afirmação que a sociedade moderna está vinculada a uma onda de desigualdades econômicas, provocadas pela globalização, especialmente na experiência brasileira, que ainda não experimentou uma adequada diferenciação funcional ou generalização da cidadania. Mostrando que pela falta de autonomia dos sistemas sociais, enfraquece-se a inclusão, emergindo relações de subintegração e sobreintegração, nos diversos subsistemas sociais.

Desse modo, uma vez que na modernidade periférica a dominação econômica tem tendências generalizantes, a democracia não se legitima, havendo uma falta de concretização normativo-jurídica, pois na prática do sobrecidadão, as disposições constitucionais são utilizadas ou rejeitadas conforme determinados interesses políticos, legitimando o uso retórico das normas constitucionais. E na prática de subcidadão, marcadamente excludentes, a Constituição, apesar de ter uma condensação rígida de princípios, não se apresenta como estrutura constitutiva dos direitos fundamentais.

Segue-se, no desenvolvimento, com a demonstração de que o Brasil vem, sobretudo vivenciando uma crise no Estado Democrático de Direito, uma vez que, os problemas estão relacionados com a conexão paradoxalmente complementar entre "legalismo" e impunidade, bloqueando à concretização normativa da Constituição, atingindo os procedimentos típicos de um Estado democrático: o eleitoral, o legislativo-parlamentar, o jurisdicional, o políticoadministrativo e a legalidade. Não se podendo falar de uma esfera pública pluralista construída com base na intermediação de dissenso de conteúdos e consenso de procedimentos.

Ao finalizar, impõe-se assim uma tentativa de enfrentar consequentemente essa conexão paradoxal de impunidade e legalismo, no sentido da construção de um espaço 
público de legalidade e constitucionalidade, e principalmente na perspectiva da generalização da cidadania, implicando uma transformação social no plano estrutural. Portanto, esforça-se pela renovação e disseminação do Estado Democrático de Direito, pois são justificáveis na medida em que ele, de adeque para a promoção da inclusão social, ao combate das desigualdades sociais provocadas pelo código econômico, a proteção integral aos direitos humanos e direitos fundamentais, efetivando a inclusão das pessoas nos sistemas funcionais e gerando reconhecimento reciproco no âmbito das interações.

\section{A COMPREENSÃO DE ESTADO DEMOCRÁTICO DE DIREITO NA TEORIA DOS SISTEMAS}

A sociedade atual se sujeita a rápidas e profundas transformações, e tais mudanças "não só afetam as formas em que se organizam a vida humana. Não só abarcam o Estado e a economia, as comunidades religiosas, o direito e a educação" (LUHMANN, 2007, p. 147). Abarcam também o ambiente e as motivações do modo de vida das pessoas na sociedade. Assim, a concepção política do Estado de bem-estar se torna um novo instrumento de governo, tratando-se de um método de "reflexão sobre o sentido, as possibilidades e os limites da política sob as condições atuais e futuras. A reflexão é um tipo de práxis que merece uma maior atenção e cuidado que geralmente é dada na atualidade frente a possíveis problemas" (LUHMANN, 2007, p. 157).

O Estado Democrático de Direito, conforme o modelo sistêmico, apresenta-se como autonomia operacional do direito. Portanto, o sistema jurídico se reproduz a partir de um código binário (lícito/ilícito) e de seus próprios programas (Constituição, leis etc.). Isso, porém, de acordo Neves, "não é o suficiente para caracterizar o Estado de Direito, que pressupõe a diferenciação dos sistemas jurídico e político, resultando em um tipo de relacionamento específico entre ambos" (2012, p. 85).

No Estado de Direito, a diferenciação da política e direito realiza-se mediante a Constituição. No entendimento teórico sistêmico, não se trata de um conceito "normativojurídico, fático-social ou culturalista, no sentido de que todo e qualquer Estado, pré-moderno ou contemporâneo, absolutista, totalitário ou democrático-liberal, tem uma Constituição" (NEVES, 2012, p. 95). A Constituição é compreendida, conforme especifica Neves, "como 
'aquisição' evolutiva da sociedade moderna. Envolve um uso linguístico inovador vinculado às transformações revolucionárias ocorridas no início da era contemporânea” (2012, p. 96).

Nesse sentido, há uma ruptura com o paradigma semântico emergente na transição para a época moderna, "no âmbito do qual a Constituição era conceituada como carta de liberdade ou pacto de poder" (NEVES, 2012, p. 96). Na acepção moderna, a Constituição poder ser compreendida como uma limitação jurídica ao governo. Também, é possível uma conceituação no sentido de que a Constituição no sentido moderno é fator e produto da diferenciação funcional entre política e direito como subsistemas da sociedade.

De acordo com esse modelo, Luhmann vai definir Constituição como acoplamento estrutural $^{3}$ entre político e direito. Assim chamado em contraste com "acoplamentos operativos (acoplamentos de operações com operações) e para distingui-lo das causalidades em curso que, se podemos expressá-lo dessa forma, ignoram ou transgridem os limites do sistema" (LUHMANN, 2016, p. 590). Existem duas variantes para os acoplamentos operativos. Uma é a chamada autopoiese, que consiste segundo Luhmann "na produção de operações do sistema por mediação das operações do sistema" (2016, p. 590). A outra reside na simultaneidade ${ }^{4}$ que sempre se deve prever entre o sistema e o ambiente.

Dessa forma, a Constituição assume a forma de acoplamento estrutural, na medida em que "possibilita influências recíprocas permanentes entre direito e política, filtrando-as. Como forma de dois, inclui e exclui, limita e facilita simultaneamente a influência entre ambos os sistemas" (NEVES, 2012, p. 97-98). Enquanto, conforme Neves, "a política é provocadora de irritações, perturbações e surpresas jurídicas, para o direito provoca irritações, perturbações e surpresas jurídicas" (NEVES, 2012, p. 98), assim, possibilita uma solução jurídica do problema de autorreferência do sistema político e, também ao contrário, uma solução política do problema de autorreferência do sistema jurídico.

Evidentemente, a noção de acoplamento estrutural não aponta para um vínculo "permanente qualquer entre direito e a política, o que implicaria um conceito 'históricouniversal' de Constituição" (NEVES, 2012, p. 98). Se tratando da teoria sistêmica, isso

\footnotetext{
${ }^{3} \mathrm{O}$ acoplamento estrutural "importa que o sistema duradouramente pressupõe e conta, no plano de suas próprias estruturas, com particularidades do seu ambiente” (NEVES, 2012. p. 97).

${ }^{4}$ Essa simultaneidade "permite um acoplamento momentâneo das operações do sistema com as que o sistema atribui ao ambiente, por exemplo, a possibilidade de cumprir com uma obrigação legal mediante ou pagamento ou sugerir consenso/dissenso político decretando uma lei” (LUHMANN, 2016, p. 590).
} 
significa a submissão explícita do código diferença "lícito/ilícito" ao código diferença “poder/não-poder".

Pode-se afirmar, em suma, que a Constituição "provê soluções políticas para o problema da autorreferência do direito e soluções jurídicas para o problema da autorreferência política" (LUHMANN, 2016, p. 641). Trata-se de uma Constituição do "Estado", ou seja, supõe-se como objetivo que demanda uma Constituição. Portanto, segundo Luhmann, é o Estado constitucional que desempenha a função de acoplamento, e assume o sentido que "para o sistema político é um instrumento político no duplo sentido de política instrumental (modificadora de decisões) e de política simbólica (não modificadora de decisões)" (LUHMANN, 2016, p. 641-642). E mesmo que se pareça uma contradição, as duas versões são compatíveis graças ao fechamento operativo dos sistemas.

Somente na perspectiva própria do sistema as circunstâncias se encontram sujeitas as modificações devidas às operações do sistema que lhes correspondam. Assim, é possível que se desenvolvam, de maneira separada, o sentido jurídico e o sentido político da Constituição, o que se torna acessível num incremento da irritação recíproca. Da mesma forma, "é concebível que em muitos países em desenvolvimento se observe que as constituições servem, quase exclusivamente, como instrumento da política simbólica” (LUHMANN, 2016, p. 642), pois ainda não houve fechamento operativo do sistema jurídico e torná-lo impermeável à influência da política e de outras forças sociais.

No entanto, Luhmann explana que "mesmo em tal caso é possível reconhecer o modelo moderno do acoplamento estrutural, ainda que unicamente como aparência verdadeira (ou seja, funcional)" (LUHMANN, 2016, p. 642). O uso simbólico das Constituições serve à política para que se proceda como se o direito a limitasse e irritasse, e para afastar as relações de poder à comunicação, num sentido pleno, a Constituição, como aquisição evolutiva, cumpre "sua função unicamente sob o pressuposto da diferenciação funcional e do fechamento operativo dos sistemas político e jurídico" (LUHMANN, 2016, p. 642).

Nesse ínterim, no âmbito do Estado de Direito e em consonância com a teoria sistêmica de acoplamento estrutural, a Constituição reingressa no interior do sistema político ${ }^{5}$

\footnotetext{
5 O sistema político se "subordina à autoirritação que subjaz à possibilidade de suscitar uma modificação jurídica. A positivação do direito representa um imenso potencial para a ação política, enquanto política em si se ocupa constantemente da seleção de tais modificações" (LUHMANN, 2016, p. 643).
} 
como mecanismo que conforme Neves “viabiliza a inserção do código 'lícito/ilícito' como segundo código da política" (2012, p. 101).

Nessa concepção, imuniza o sistema político em relação às pressões particulares concretas, trata-se como Neves explica, de uma “imunização jurídica recepcionada internamente pelo sistema político na construção de sua própria autonomia” (2012, p. 101). Essa imunização envolve a institucionalização do procedimento eleitoral democrático que serve de empecilho à manipulação do sistema político "por interesses particularistas e encerra, indissociavelmente, a formação pluripartidária do parlamento, incompatível como o mandato imperativo" (NEVES, 2012, p. 102). Com isso, protege o sistema político, por meio da instituição da divisão de poderes contra uma expansão destrutiva da própria autonomia.

Como acoplamento estrutural entre política e direito, e assim, por reingresso, meios de "autonomia de cada um desses sistemas, a Constituição do Estado Democrático de Direito institucionaliza tanto o procedimento eleitoral e a 'divisão dos poderes' quanto os direitos fundamentais" (NEVES, 2012, p. 102). Aqueles formam exigências primariamente políticas, estes, jurídicas. Porém, trata-se de instituições inseparáveis na caracterização do Estado Democrático de Direito.

\section{O PROBLEMA DO ESTADO DEMOCRÁTICO DE DIREITO NA MODERNIDADE PERIFÉRICA}

A experiência brasileira apresenta-se como um caso típico de modernidade periférica $^{6}$, desde que a "crescente complexidade e o desaparecimento do moralismo tradicional não têm sido acompanhados de maneira satisfatória pela diferenciação funcional e pelo surgimento de uma esfera pública fundada institucionalmente na universalização da cidadania" (NEVES, 2018, p. 244). O modelo "centro/periferia" enfatiza que o tratamento de

\footnotetext{
${ }^{6}$ Marcelo Neves ao tratar da sociedade mundial atual recorre ao esquema "centro/periferia" e, assim, trata-se de uma modernidade periférica. A divisão da modernidade em "centro e periferia é, primeiramente, uma questão econômica que encontra espaço no âmbito da discussão sobre as condições de surgimento do capitalismo. Mas ela tem implicações para todos os sistemas funcionais da sociedade. Não se deve, contudo, interpretar a distinção como se com ela a multiplicidade da sociedade mundial atrial fosse deixada de lado: a relação 'centro/periferia' reproduz-se entre os países periféricos e tanto no interior das 'nações periféricas' quando das 'nações centrais'. Os diferentes tipos dos contextos internos de interesses de classe e de dominação implicam formas distintas de integração dos países periféricos na sociedade mundial; além disso, as particularidades locais e regionais atuam como fatores do desenvolvimento; ademais, os diferentes sistemas funcionais encontram-se em níveis de desenvolvimento muito diferentes também no plano regional" (NEVES, 2018, p. 102-103). Portanto, com essas considerações, usa-se "centro/periferia", que se refere a uma divisão dicotômica e heterárquicas da sociedade, e assim introduzir o conceito de "modernidade periférica" como construção "típico-ideal".
}

Revista de Sociologia, Antropologia e Cultura Jurídica | e-ISSN: 2526-0251 | Porto Alegre | v. 4 | n. 2 | p. $126-145$ | Jul/Dez. 2018 
uma e da mesma sociedade mundial ${ }^{7}$, não de sociedades modernas versus sociedades tradicionais, persuadindo que uma diferença de "antes e depois" estivesse na base dos diferenciados níveis de desenvolvimento social.

Com efeito, de uma concepção política-jurídica, pode-se pensar em sociedades regionais: "por falta de unidade mundial na formação jurídica e política, a sociedade mundial não é uma unidade constituída por estruturas normativas de expectativa, não sendo, portanto, nem um império mundial nem um sistema internacional” (NEVES, 2018, p. 104). Mas quando enfatizado que a sociedade atual se baseia, primariamente, em "estruturas cognitivas de expectativa, mais precisamente na economia, e que a diferenciação segmentária das sociedades regionais, assentadas nos sistemas jurídico e político, possui uma posição 'subordinada"” (NEVES, 2018, p. 104), entende-se que os problemas dos países periféricos pertencem, primordialmente, às questões fundamentais da sociedade moderna/mundial. A modernização periférica pode ser compreendida como "integração subordinada de um país na sociedade mundial, sob proteção do respectivo sistema político-jurídico regional” (NEVES, 2018, p. 105).

Não cabe ignorar, que a sociedade mundial do presente é multifacetada e possibilita a aplicação do esquema "centro e periferia" em vários níveis. A distinção entre a modernidade central e periférica é analiticamente propícia, na medida em que, "definindo-se a complexidade social e o desaparecimento de uma moral imediatamente válida para todas as esferas da sociedade como características da modernidade" (NEVES, 2011, p. 171), verificase que, em algumas regiões estatalmente delimitadas (países periféricos), "não houve a efetivação da autonomia sistêmica de acordo com o princípio da diferenciação funcional nem a constituição de uma esfera pública fundada na generalização institucional da cidadania" (NEVES, 1994, p. 66), características de outras regiões estatalmente organizadas (países centrais) - pelo menos aparentes -.

A bifurcação no desenvolvimento da sociedade moderna (mundial) trouxe para os países periféricos em uma "crescente e veloz complexificação social, sem que daí surgissem sistemas sociais capazes de estruturar ou determinar adequadamente a emergente

\footnotetext{
${ }^{7}$ Numa perspectiva sistêmica-teórica, Niklas Luhmann trata a sociedade moderna como "sociedade mundial", orientada primariamente pela econômica, a técnica e a ciência, o qual, entretanto, sem coerência com essa concepção, aplicava o modelo "tradição/modernidade" à diferença entre países em desenvolvimento e países desenvolvidos (LUHMANN, 1980. p. 57).
}

Revista de Sociologia, Antropologia e Cultura Jurídica | e-ISSN: 2526-0251 | Porto Alegre | v. 4 | n. 2 | p. $126-145$ | Jul/Dez. 2018 
complexidade" ${ }^{\prime 8}$ (NEVES, 2011, p. 172). Os respectivos sistemas não se desenvolvem, pois, com suficiente autonomia operacional. Com isso, relaciona-se o problema da "heterogeneidade estrutural", cuja "discussão remete às abordagens sobre desenvolvimento das teorias de dependência e periferia elaboradas nos anos 1960 e 1970" (NEVES, 2018, p. 108). Nessa constelação, apontou-se, sobretudo, que a questão das grandes diferenças no interior de todos os sistemas sociais e entre eles, a que se referia o conceito contestado de "heterogeneidade estrutural", "provocando um difuso sobrepor-se e intrincar-se de códigos e critérios/programas tanto entre os subsistemas sócias quanto no interior deles" (NEVES, 2011, p. 172), enfraquecendo ou impossibilitando o seu funcionamento de maneira generalizadamente includente.

Daí surge o problema da "marginalidade" ou "exclusão"9 (NEVES, 2014, p. 180183), que, é um problema de "subintegração" 10 nos sistemas funcionais da sociedade. Sob uma perspectiva sistêmico-teórica, a "marginalidade" significa uma "subintegração social difusa e muito instável de grande parte da população nos diferentes sistemas funcionais, que se intensifica com a modernização periférica" (NEVES, 2018, p. 109). Surgem, então, relações de "subintegração" e "sobreintegração"11 nos diversos subsistemas sociais, bloqueando-lhes a reprodução autopoiética.

Embora a distinção ideal entre "centro" e "periferia" da sociedade moderna tenha um cunho fundamentalmente econômico, ela pressupõe a segmentação territorial do sistema político-jurídico em Estados. Quando à modernidade periférica, o problema estrutural desde o seu surgimento vincula-se à "falta de suficiente autonomia operacional dos sistemas jurídico e político, bloqueados externamente por injunções diretas (isto é, não mediatizadas por suas próprias operações) de critérios dos demais sistemas sociais, principalmente do econômico"

\footnotetext{
${ }^{8}$ Sobre a distinção entre complexidade estruturada e não-estruturada, ver (LUHMANN, 1998).

9 Sobre "marginalidade" na discussão dos anos 1960 e 1970 em torno do capitalismo de dependência e capitalismo periférico, ver, em (CARDOSO, 1979). Sobre "inclusão/exclusão" na teoria sistêmica, ver (LUHMANN, 1998).

10 "Subintegração" significa aqui "bloqueio prático do acesso positivo (no próprio interesse do agente) aos sistemas sociais modernos existentes (economia, política, direito, educação etc.), os quais então afetam os 'marginalizados' apenas negativamente (por exemplo, como devedor, não como credor; como réu, não como autor). Com base nos ensinamentos de Luhmann, pode-se designar 'marginalização' como exclusão, mas não no sentido de não integração de grupos populacionais inteiros, mas de sua dependência das prestações dos diferentes sistemas funcionais da sociedade (subintegração), sem acesso (no sentido positivo) a elas" (NEVES, 2018. p. 109-110). Em suma, a "subintegração" significa "dependência dos critérios do sistema (político, econômico, jurídico etc.) sem acesso às suas prestações" (NEVES, 2011. p. 173).

${ }^{11}$ A "sobreintegração" implica "acesso aos benefícios do sistema sem dependência de suas regras e critérios" (NEVES, 2011. p. 173).
} 


\section{A RUPTURA DEMOCRÁTICA NA MODERNIDADE PERIFÉRICA: A GENERALIZAÇÃO DAS RELAÇÕES DE SUBINTEGRAÇÃO E SOBREINTEGRAÇÃO}

(NEVES, 2011. p. 173). Na linguagem sistêmica, os mecanismos de filtragem seletiva do direito positivo (princípios da legalidade, da constitucionalidade etc.) e do sistema político (eleições livres, secretas e universais, organização partidária etc.) não funcionam adequadamente em relação às "pressões bloqueantes do código binário de preferência ‘ter/não-ter', como também do código do amor, da religião, da amizade etc.” (NEVES, 2011. p. 173). Internamente, por sua vez, não há um funcionamento satisfatório da Constituição como "acoplamento estrutural" entre direito e política, ou seja, como "mecanismo de interpretação e interferência entre dos sistemas autônomos, antes um bloqueio recíproco, principalmente no sentido da politização desdiferenciante do sistema jurídico"12 (NEVES, 2011. p. 173-174). Assim, nesse contexto, direito e política constituem sistemas alopoieticamente determinados, na medida em que não se reproduzem operacionalmente por elementos próprios, diferenças e critérios, "mas não se difusa e instavelmente invadidos, na sua reprodução operacional, por diferenças, critérios e elementos de outros sistemas sociais" (NEVES, 2011, p. 174).

Mesmo se admitindo que os critérios de filtragem destinados a assegurar a autonomia do direito e do sistema político, como por exemplo, o princípio da igualdade perante a lei e o das eleições democráticas, constituem ilusões ideológicas na modernidade central, devendo-se reconhecer que, na modernidade periférica, nem nesse sentido elas funcionam adequadamente: "entre outras, as injunções particularistas da dominação econômica realizamse de forma desnuda, destruindo abertamente e com tendências generalizantes a legalidade no plano jurídico e os procedimentos democráticos na esfera política” (NEVES, 2011, p. 174). Também entre direito e política, "a aplicação controladora e limitante do código 'lícito/ilícito' com segundo código do sistema político, caraterística do 'Estado de direito', não se realiza de forma satisfatória" (LUHMANN, 2002, p. 165), sendo constatada a ingerência ilícita sistemática do poder sobre o direito.

Presumindo que o Estado periférico se caracteriza pelo pêndulo entre instrumentalismo ${ }^{13}$ e nominalismo constitucional, interessa aqui a predominância simbólica

\footnotetext{
${ }^{12}$ Não se nega aqui ingenuamente que essa situação seja "funcional" em outras perspectivas e para determinados setores. Mas não é funcional no sentido de "inclusão" de toda a população nos respectivos sistemas autônomos da sociedade (LUHMANN, 1994, p. 35).

${ }^{13}$ Não se desconhece que as "Constituições instrumentalistas" também desempenham funções simbólicas, entretanto, "o que as distingue é que atuam, antes de tudo, como simples instrumentos ('armas') jurídicos dos 'donos de poder"' (NEVES, 2011. p. 175).
} 
das "Constituições nominalistas", no qual, implicam a "falta de concretização normativojurídica do texto constitucional em conexão com a relevância simbólica dele no discurso constitucionalista do poder (constitucionalização simbólica)" (NEVES, 2011, p. 175). Nesse contexto, Luhmann aclara que nas "relações de subintegração e sobreinegração políticojurídica, não se desenvolve Constituição como horizonte normativo-jurídico do sistema político" (1980, p. 159). Em prática do "sobrecidadão" as "disposições constitucionais são utilizadas, abusadas ou rejeitadas conforme a constelação concreta de interesses políticos" (PIAGET, 1975, p. 146). No agir e vivenciar do "subcidadão" a Constituição apresenta-se antes como "complexo de restrições oficiais corporificadas nos órgãos e agentes estatais, não com estrutura constitutiva de direitos fundamentais" (NEVES, 2011, p. 175). A ausência de concretização normativo-jurídica generalizada da Constituição se relaciona com um discurso fortemente constitucionalista nas práxis política.

Aos agentes governamentais que se vinculam em regra à "sobrecidadania", o discurso político aponta para a "identificação do governo ou do Estado com os 'valores' consagrados no documento constitucional” (NEVES, 2011, p. 175). Sendo evidente que esses valores não encontram amparo na realidade constitucional do presente. Já no discurso dos grupos interessados em reais transformações nas relações de poder, os quais representam a "subcidadania", invocam-se os direitos constitucionais para denunciar os atos inconstitucionais e atribuir ao Estado/governo dos "sobrecidadãos" a "culpa" pela não efetivação dos direitos constitucionais.

Evidentemente, que nas condições de constitucionalização simbólica da modernidade periférica, caraterizada pelas relações de "subintegração" e "sobreintegração" não só no sistema jurídico-político, mas também nos sistemas econômico, educacional, da saúde etc., tornam-se inadequados, "o tratamento e a solução do problema da ineficácia da legislação constitucional com base no esquema instrumental 'meio-fim' das 'pesquisas de implementação"” (NEVES, 2011, p. 176). Isso se dá, porque a constitucionalização simbólica afeta amplamente as dimensões social, material e temporal do sistema jurídico, mas sobretudo porque a concretização normativa da Constituição pressuporia uma revolução nas relações de poder.

\section{EXPERIÊNCIA BRASILEIRA: A GENERALIZAÇÃO DE RELAÇÕES DE SUBINTEGRAÇÃO E SOBREINTEGRAÇÃO}




\section{A RUPTURA DEMOCRÁTICA NA MODERNIDADE PERIFÉRICA: A GENERALIZAÇÃO DAS RELAÇÕES DE SUBINTEGRAÇÃO E SOBREINTEGRAÇÃO}

Conforme enfatizado, as condições negativas da realização do Estado Democrático de Direito na modernidade periférica, "relacionam-se antes de tudo com os limites à autoreferência dos sistemas político e jurídico" (NEVES, 1994, p. 253-276). Essa situação tornase grave, pois emergem expressivos problemas de heterorreferência do Estado em uma sociedade mundial supercomplexa e, simultaneamente, perduram destrutivamente os bloqueios generalizados à reprodução autônoma dos sistemas político e jurídico, "minando a Constituição como acoplamento estrutural entre ambos e como intermediação sistêmicoprocedimental da esfera pública pluralista" (NEVES, 2012, p. 236-237).

Essas observações gerais sobre a modernidade periférica tornam-se sobretudo importantes quando se considera o problema dos obstáculos à realização do Estado Democrático de Direito. A partir do envolvimento da sociedade, os sistemas jurídico e político são bloqueados generalizadamente na sua autoprodução consistente por injunções heterônomas de outros códigos e critérios sistêmicos, assim como "pelos particularismos difusos que persistem na ausência de uma esfera pública pluralista” (NEVES, 2012, p. 237). No interior do Estado, por sua vez, se verificam intrusões destrutivas do poder na esfera do direito.

Em face da sociedade como conjuntura do Estado, se pode indagar sobre a alopoiese ${ }^{14}$ social do direito por "força da prevalência de outros códigos de preferência sobre o código "lícito/ilícito"” (NEVES, 1995, p. 117-141). Neves elucida que isso significa "que não estão definidas claramente as fronteiras da juridicidade" (1995, p. 7-37). Não somente a preferência "ter/não-ter" atua no impedimento da reprodução sistemicamente autoconsistente do direito. Porém, de fato, em decorrência das discrepâncias entre as camadas sociais, o código econômico se reproduz hipertroficamente, implicando privilégios e "exclusões" ilegais. Assim sendo, a legalidade como generalização igualitária de conteúdos jurídicos é

\footnotetext{
${ }^{14} \mathrm{O}$ conceito de alopoiese se contrapõe do modelo luhmanniano do direito moderno (positivo) autopoiético, pois se relaciona com o estado de corrupção sistêmica. A alopoiese segundo Hommerding e Lyra, "cuida-se da falta de autonomia operacional do direito, que é invadido/corrompido por outros códigos, não conseguindo forjar sua legalidade, perdendo a condição de reflexão/reflexividade" (2014. p. 99). Portanto, ainda segundo os autores, a alopoiese ocorre quando o "código do Direito não consegue alcançar determinados âmbitos da sociedade, na medida em que sofrem bloqueios, especialmente pelo sistema econômico e seu metacódigo (inclusão/exclusão), ou ainda, quando é invadido por outros subsistemas, perdendo sua autonomia". (2014, p. 99). E, nesse passo, Lyra nota que o "problema das sociedades atuais e sua diferenciação funcional é que há uma diferença abismal entre inclusão/exclusão, que acaba bloqueando o acesso de grandes contingentes populacionais à comunicação dos sistemas funcionais" (2012, p. 258).
}

Revista de Sociologia, Antropologia e Cultura Jurídica | e-ISSN: 2526-0251 | Porto Alegre | v. 4 | n. 2 | p. $126-145$ | Jul/Dez. 2018 
alterada no processo de concretização do direito, sendo que, no pensar do caso brasileiro, prevalecem formas unilaterais de legalismo e de impunidade em relação paradoxal de complementaridade.

Partindo da análise sistêmica, abertura cognitiva pressupõe fechamento operacional ou normativo. Assim, antes se trata da ruptura do fechamento operacional, por força da qual se diluem os limites entre o campo jurídico e outras esferas de comunicação. O resultado disso, é que o direito se encontra permanentemente em crises de identidade no Estado Democrático de Direito da modernidade periférica. Além do mais, cabe observar que não se trata simplesmente de fenômenos de "corrupção sistêmica em detrimento dos acoplamentos estruturais no âmbito das organizações, tal como se observa em experiências do Estado Democrático de Direito na Europa Ocidental e na América do Norte” (LUHMANN, 2016, p. 445), pois os conceitos pressupõem a autopoiese dos respectivos sistemas. No ensinamento de Neves, a "corrupção sistêmica tem tendência à generalização em experiências jurídicas típicas da modernidade periférica, atingindo o próprio princípio da diferenciação funcional e resultando no alopoiese do direito" ${ }^{15}$ (2012, p. 241).

Essas considerações sobre as dificuldades à realização do Estado Democrático de Direito na modernidade periférica devem desconsiderar a ideia de uma "legalidade rígida em face dos problemas sociais, assim como o mito de um Estado forte diante uma sociedade frágil” (NEVES, 2012, p. 243), em ambos os casos, tem-se uma concepção de que o problema reside primariamente na inadequada heterorreferência. Na realidade, "trata-se anteriormente de fragilidade do Estado perante as coerções de uma sociedade desestruturada pela insuficiência de diferenciação funcional e a ausência de uma esfera pública pluralista" (NEVES, 2013, p. 105-147), fundada na universalidade da cidadania.

A democracia brasileira, enquadrada como um típico caso de modernidade periférica, implica grandes obstáculos, obviamente não considerando às experiências autoritárias de 1937-45 e 1964-84. Nesses casos, tem-se uma negação direta e expressa do Estado de Direito. Pode-se afirmar que o modelo das Constituições de 1824, 1891, 1934, 1946 e 1988, teria um forte desenvolvimento do Estado de Direito no Brasil, no entanto, no que se refere a

\footnotetext{
${ }^{15}$ Luhmann reconhece que, "em caso extremo" de "corrupção sistêmica", "não se pode mais falar de fechamento autopoiético", mas não retira daí as devidas consequências empíricas para a sua construção teórica, tendo em vista que insiste na tese do primado da diferenciação funcional na sociedade mundial (LUHMANN, 2016. p. 572).
} 
concretização, não se observou um corresponde crescimento. Evidentemente, o Brasil é mercado por formas de "instrumentalização política, econômica e relacional de mecanismos jurídicos, apontando no sentido inverso à indisponibilidade do direito" (NEVES, 2012, p. 246). Há uma tendência a desrespeitar os procedimentos previstos no texto constitucional, de acordo com conformações concretas de poder, conjunturas econômicas e códigos relacionados. Isso está fortemente relacionado à persistência de privilégios e "exclusões" que impedem a construção de uma esfera pública universalista como espaço de comunidade entre cidadãos abarcados pela igualdade.

Um dos maiores obstáculos que dificultam a realização do Estado Democrático de Direito, na modernidade periférica, especialmente no Brasil, é a generalização de relações de subintegração e sobreintegração. Definida a "inclusão como acesso e dependência aos sistemas sociais" (LUHMANN, 1994, p. 25), faltando nesse caso uma das duas dimensões do conceito. Neves aclara que não se trata, a rigor, "de relações alopátricas de exclusão entre grupos humanos no espaço social, antes de formas subordinadas ou sobreordenadas de integração social" (2012, p. 248). Interessa nesse contexto, o problema de falta de generalizada de inclusão no sistema jurídico, no sentido da ausência de direitos e deveres partilhados de maneira recíproca. Isso significa "inexistência de cidadania como mecanismo de integração jurídico-político igualitária da população na sociedade” (NEVES, 1994, p. 253276).

Os subintegrados, se generalizam em situações em que não têm acesso aos benefícios do ordenamento jurídico estatal, mas dependem de suas prescrições impositivas. Portanto, os "subcidadãos" não estão excluídos como um todo. Embora lhes faltem as condições de exercer os "direitos fundamentais constitucionalmente declarados, não estão liberados dos deveres e responsabilidades impostas pelo aparelho coercitivo estatal, submetendo-se radicalmente às suas estruturas punitivas" (NEVES, 2012, p. 248). Para os subintegrados, os dispositivos constitucionais têm relevância apenas em seus efeitos restritivos a liberdade. Os direitos fundamentais não atuam em nenhum papel significativo no seu sentido de vivenciar e agir, inclusive no que tange à identificação de sentido das normas constitucionais. No campo constitucional que o problema da subintegração ganha evidência, na medida em que, relacionando os membros das camadas sociais "subalternas", os danos aos direitos 
fundamentais são praticados principalmente nos "quadros da atividade repressiva do 'aparelho estatal', ou seja, das ações violentas ilegais da polícia” (OLIVEIRA, 1994).

A subintegração é inseparável da sobreintegração. Está se refere à "prática de grupos privilegiados que, desenvolvem suas ações bloqueantes da reprodução do direito" (NEVES, 2012, p. 250). Os sobreintegrados, em tese, são portadores de direitos, competências, poderes e prerrogativas, e não são subordinados regularmente à atividade punitiva do Estado, especificamente, no que se refere aos deveres e responsabilidades. Nesse contexto, o direito não se apresenta como instrumento do agir e vivenciar político-jurídico do sobrecidadão, mas sim como um meio de alcance de seus objetivos econômicos, políticos e relacionais.

Se tratando da sociedade mundial supercomplexa atual, ninguém é absolutamente subintegrado ou sobreintegrado, pois as posições correspondentes dependem de condições fáticas da reprodução das comunicações, havendo momentos que o subcidadão pode ser um sobreintegrado, e vice-versa. No entanto, a generalização de relações de subintegração e sobreintegração fazem "implodir a Constituição como ordem básica da comunicação jurídica e também como acoplamento estrutural entre política e direito. Isso tem efeitos alopoiéticos, especialmente com relação à esfera jurídica" (NEVES, 2012, p. 251). De fato, a autoreferência sistêmica e a diferenciação funcional implicam a inclusão generalizada da população nos diversos subsistemas sociais.

No sentido de uma interpretação de que a sociedade moderna (mundial) se caracteriza pelo princípio da diferenciação funcional, pressupondo que toda população estaria incluída nos diversos sistemas funcionais, implica uma restrição crítica. Luhmann reviu seu posicionamento com respeito à diferença “inclusão/exclusão" (2007, p. 603), afirmando que ela funciona como uma "metadiferença ou metacódigo, que mediatiza os códigos de todos os sistemas funcionais" (LUHMANN, 2007, p. 602). Também em pensamento diverso do modelo de subintegração e sobreintegração, Luhmann distingue, em sua obra tardia (1998), entre "setor de inclusão" (no qual, os seres humanos são tratados como pessoas) e "setor da exclusão" (em que há seres humanos que não são considerados pessoas, senão como corpos), assim a integração ${ }^{16}$ é compreendida como "redução dos graus de liberdade de subsistemas ou

\footnotetext{
${ }^{16}$ Na obra de Luhmann, a expressão "integração" é empregada com relação ao problema da "inclusão/exclusão", sem que haja univocidade a esse respeito.
}

Revista de Sociologia, Antropologia e Cultura Jurídica | e-ISSN: 2526-0251 | Porto Alegre | v. 4 | n. 2 | p. $126-145$ | Jul/Dez. 2018 
como limitação dos graus de liberdade para seleções” (LUHMANN, 2007, p. 603) e, portanto, “negativamente como dependência, não como acesso" (LUHMANN, 2007, p. 618).

Entretanto, na formulação ${ }^{17}$ de Neves, subintegração e sobreintegração implicam a “insuficiente inclusão, seja, respectivamente, por falta de acesso (de integração positiva) ou de dependência (de integração negativa), constituindo posições hierárquicas facticamente condicionadas (não classificações baseadas em princípio)" (NEVES, 2012, p. 253), a saber, o de ser integrado nos sistemas funcionais. Trata-se de "limitação e unilateralidade na capacidade de imputação dos sistemas sociais em suas referências as pessoas" (NEVES, 2012, p. 253).

No âmbito do direito, significa que os sobreintegrados têm acesso aos direitos (às vias e garantias jurídicas), sem se vincularem aos deveres e às responsabilidades impostas pelo sistema jurídico. Os subintegrados, ao contrário, não dispõe de acesso aos direitos, às vias e garantias jurídicas, embora estejam totalmente subordinados aos deveres, às responsabilidades e às penas restritivas de liberdade. Por essa razão que, os subcidadãos e os sobrecidadãos são carentes de cidadania, que, como mecanismo "político-jurídico de inclusão social, pressupõe igualdade não apenas em relação aos direitos, mas também a respeito dos deveres" (NEVES, 2012, p. 254), envolvendo uma relação bilateral de direitos e deveres fundamentais generalizados.

Esse problema, no Brasil, se relaciona com a conexão entre legalismo e impunidade. De um lado, o legalismo implicando um "autismo jurídico", no qual, não se constrói interpretação-aplicação jurídica que, sem negar a diferenciação funcional do direito, se orienta nas consequências sociais das decisões jurídicas. Vale ressaltar, que não se deve confundir esse "autismo" de legalismo com a afirmação do princípio da legalidade, este exige a generalização legal, importando o acesso de todos os cidadãos ao direito. O "fetichismo da lei no Brasil é unilateralista, funciona como mecanismo de descriminação social" (NEVES, 2012, p. 254), dirigindo-se, aos subintegrados. Trata-se de falta de acesso ao direito e, assim, de "exclusão" social. Em suma, os referidos grupos sociais/pessoas só são considerados pelo legalismo unilateral quando entram em contato com o sistema em seu desfavor, ou seja, como

\footnotetext{
${ }^{17}$ Neves conceitua integração social como "uma relação bem-sucedida de liberdade e vínculo, pode-se definir, no sentido proposto, subintegração como vínculo sem liberdade (ou melhor, vinculo rígido e liberdade restrita) e sobreintegração como liberdade sem vínculo (ou melhor, vínculo flexível e liberdade ampla) das pessoas em face dos sistemas sociais (2012. p. 253).
}

Revista de Sociologia, Antropologia e Cultura Jurídica | e-ISSN: 2526-0251 | Porto Alegre | v. 4 | n. 2 | p. $126-145$ | Jul/Dez. 2018 
culpados, presos etc., não como detentores de direitos. Caso que se configura como subintegração no sistema jurídico, os indivíduos estão subordinados as coerções, mas não têm acesso aos direitos.

Também, de outro lado, a relação entre direito e realidade social na experiência brasileira tem sido marcada pela impunidade. Observa-se que ilícitos, especialmente na área criminal, não são seguidos das sanções preestabelecidas juridicamente, sendo que, a “impunidade está vinculada ao mundo dos privilégios, pelo apadrinhamento político, pela troca de favores e concessões baseadas pela amizade, interesses políticos e, também em trocas ilícitas (por exemplo: a fraude em licitações)" (NEVES, 2007, p. 161), isso tudo diz respeito aos sobreintegrados juridicamente. Estes podem conduzir suas ações contando de que não serão punidos em caso de transgressões à ordem jurídica. A conexão entre legalismo e impunidade "obstaculiza a estruturação de uma esfera pública de legalidade e, portanto, a realização do Estado Democrático de Direito” (NEVES, 2012, p. 256).

Esses obstáculos à realização do Estado de Direito no Brasil se manifestam no plano constitucional, uma vez que, definida a Constituição como acoplamento estrutural entre política e direito como estrutura normativa mais abrangente do sistema jurídico, verificam-se bloqueios sociais que destroem sua concretização, deixando o texto constitucional não correspondendo às expectativas normativas congruentemente generalizadas, faltando-lhe assim relevância jurídica, ou seja, carente de força normativa.

Os bloqueios à concretização normativa da Constituição atingem os procedimentos essenciais do Estado Democrático de Direito: “o eleitoral mobilizador das mais diversas forças políticas em luta pelo poder; o legislativo-parlamentar, construído pela discussão livre entre oposição e situação; o político-administrativo, orientado por critérios de constitucionalidade e legalidade" (NEVES, 2012, p. 257). Assim, não se pode pensar em uma esfera pública pluralista construída com base na intermediação de dissenso conteudístico e consenso procedimental. O Estado Democrático de Direito se realiza por um conjunto de variáveis complexas, ou seja, pela declaração constitucional dos procedimentos legitimadores, de fatores socioeconômicos e culturais que possam viabilizar a superação de relações de subintegração e sobreintegração.

Impõe-se assim combater consequentemente a conexão paradoxal de legalismo e impunidade, no sentido da construção de um espaço público de legalidade e 
constitucionalidade, pressupondo "inclusão das pessoas nos sistemas funcionais e reconhecimento reciproco no âmbito das interações" (NEVES, 2013, p. 129), gerando uma perspectiva generalizada de cidadania.

\section{CONCLUSÃO}

Em relação ao fato de que o Estado Democrático de Direito se encontra sob uma grande tensão na perspectiva da sociedade mundial e dos conflitos étnicos e fundamentalistas religiosos, enfraquecendo sua capacidade funcional e força interativa, precisa-se buscar mecanismos, procedimentos e instituições jurídicas e políticas que possam apresentar alternativas à sua incapacidade regulatória e deficiência funcional. No caso da experiência brasileira, apresentada como um caso típico de modernidade periférica, no qual, se espera um surgimento adequado de uma esfera pública fundada institucionalmente na universalização da cidadania e uma satisfatória orientação nas noções de democracia como inclusão política generalizada e de Estado de bem-estar como promotor da efetiva inclusão.

No Brasil, apesar de evolutivamente adotar o modelo textual de constitucionalismo democrático social, se revela em condições de exclusão de amplas parcelas da sociedade e de privilégios de uma parcela minoritária persistem, e apesar, que nas últimas décadas tenha havido relevantes inserções em temas jurídicos com relevância moral e social, esses permanecem no campo de reconhecimento de grupos, sem de fato, acontecer um grande impacto na questão da exclusão de origem primariamente econômica. E, esse contexto se agrava a partir do impeachment da presidente Dilma Rousseff e a consequente admissão ao cargo de presidente por Michel Temer em 2016.

A partir do processo de impeachment, a diferença que constitui a política seguindo o modelo de Carl Schmitt (2009), "amigo/inimigo", passa a ter um significado típico de regimes autocráticos ou de regimes de "exceção", sendo que, na democracia, a diferença amigo/inimigo cede à diferença aliado/adversário (NEVES, 2018, p. 413). Atualmente, o Estado brasileiro passa por uma forte ruptura democrática, uma vez que, proliferam (exemplo, intervenção militar no Estado do Rio de Janeiro) a excepcionalidade das leis, que primam por suspender a Constituição e seu sistema de garantias. Sob essa perspectiva, quando se detecta o surgimento de um Estado de exceção (AGAMBEN, 2004, p. 13), o qual prima pela suspensão do Direito do estado (o direito se converte na razão do Estado, ou um ato de pura força sem 
lei), negando radicalmente a fundamentação jurídica das recentes intervenções militares pretensamente destinadas à imposição dos direitos humanos, potencializando o problema da "exclusão", que, é um problema de "subintegração" nos sistemas funcionais da sociedade. Surgindo, então, relações de "subintegração" e "sobreintegração" nos diversos subsistemas sociais, bloqueando-lhes a reprodução autopoiética. Com tal "exclusão e consequente perda de expectativas sociais mais pretensiosas, a sociedade se topa com grupos coletivos que não dispõem de qualquer visibilidade social" (HONNETH, 2011. p. 127-145.) e, e por isso não contam nas ações oficiais das organizações, pois tem a comunicação bloqueada por não possuírem influência.

Conforme o que foi apresentado, verifica-se uma crise democrática que é fortemente abalada pela conexão paradoxalmente complementar entre "legalismo" e impunidade, e consequentemente implicando a insuficiente inclusão. Assim, se cria a expectativa na construção de um regime de bem-estar renovado, o Estado Democrático de Direito deve criar possibilidades político-jurídicas estruturais favoráveis a uma preferência por inclusão, podendo forjar uma ordem estável no domínio dos direitos humanos, em que lhes proporcione implementação e proteção.

A "re"moralização do sistema jurídico e político devem ser refletidos por meio de uma teoria sociológica da moral (LUHMANN, 2013), fortalecendo a reflexão ética como teoria da moral, para assim, criar esforços pela renovação e disseminação do Estado Democrático de Direito que são legitimadas na medida em que se apresenta como uma forma político-jurídica mais adequada e bem-sucedida para a promoção da inclusão social, em tempos de crise democrática, especialmente nas conjunturas dos países que se encontram na modernidade periférica, o combate ao expansionismo destrutivo e excludente do sistema econômico, a proteção dos direitos humanos e direitos fundamentais e ainda na confrontação com os fundamentalistas, é a questão que se põe em máxima urgência. Se trata, em conviver em sociedade buscando respeitar e potencializar a democracia, lutar pelas desigualdades sociais, combater o ódio que se instaurou no código amigo/inimigo, visando a melhoria e novos papéis, tarefas e possibilidades do Estado Democrático de Direito em uma sociedade supercomplexa mundial.

\section{REFERÊNCIAS}

Revista de Sociologia, Antropologia e Cultura Jurídica | e-ISSN: 2526-0251 | Porto Alegre | v. 4 | n. 2 | p. $126-145$ | Jul/Dez. 2018 
AGAMBEN, Giorgio. Estado de exceção. Tradução de Iraci D. Poleti. São Paulo: Boitempo, 2004.

CARDOSO, Fernando Henrique. O modelo político brasileiro e outros ensaios. $4^{\text {a }}$. ed. São Paulo: Difel, 1979.

HOMMERDING, Adalberto Narciso; LYRA, José Francisco Dias da Costa. Racionalidade das leis penais e legislação simbólica. 1. ed. Rio de Janeiro: LMJ Mundo Jurídico, 2014.

HONNETH, Axel. La sociedad del desprecio. Tradução de Francesc J. Hernández e Benno Herzog. Madrid: Trotta, 2011.

LUHMANN, Niklas. Complejidade y modernidad: de la unidad a la diferencia. Tradução de Josetxo Berian e José María García Blanco. Madrid: Trotta, 1998.

LUHMANN, Niklas. El Derecho de la Sociedade. México: Universidad Iberoamericana, 2002.

LUMANN, Niklas. La moral de la sociedad. Madrid: Editorial Trotta, 2013.

LUHMANN, Niklas. Legitimação pelo procedimento. Brasília: UnB, 1980.

LUHMANN, Niklas. O direito da sociedade. Tradução Saulo Krieger; Tradução das citações em latim Alexandre Agnolon. São Paulo: Martins Fontes, 2016.

LUHMANN, Niklas. Sistemas sociales: lineamientos para una teoria general. $2^{\mathrm{a}}$. ed. Barcelona: Ceja, 1998.

LUHMANN, Niklas. Teoría política en el Estado de bienestar. Madrid: Alianza Universidad, 2007.

LUMANN, Niklas. La sociedad de la sociedad. Tradução de Javier Torres Nafarrate. México: Herder, 2007.

LYRA, José Francisco Dias da Costa. A moderna sociedade do risco e o uso político do controle penal ou a alopoiesis do direito penal. In: Revista Brasileira de Ciências Criminais, São Paulo, v. 95, p. 258, 2012.

NEVES, Marcelo. A constitucionalização simbólica. São Paulo: Martins Fontes, 2011.

NEVES, Marcelo. A Constituição e a esfera pública: entre diferenciação sistêmica, inclusão e reconhecimento. In: Dossiê Niklas Luhmann. Roberto Dutra, João Paulo Bachur, Organizadores. Belo Horizonte: Editora UFMG, 2013.

NEVES, Marcelo. A crise do Estado: da modernidade central à modernidade periférica Anotações a partir do pensamento filosófico e sociológico alemão. In: Revista de Direito Alternativo 3. São Paulo: Acadêmica, 1994. 
NEVES, Marcelo. Constituição e direito na modernidade periférica: uma abordagem teórica e uma interpretação do caso brasileiro. São Paulo: Martins Fontes, 2018.

NEVES, Marcelo. Da autopoiese à alopoiese do direito. In: Revista Brasileira de Filosofia, vol. XLII. São Paulo: Instituto Brasileiro de Filosofia, 1995.

NEVES, Marcelo. Do pluralismo jurídico à miscelânea social: o problema da falta de identidade da(s) esfera(s) de juridicidade na modernidade periférica e suas implicações na América Latina. In: Direito em Debate, ano V, n. ${ }^{\circ}$ 5. Ijuí: Universidade de Ijuí, 1995.

NEVES, Marcelo. Entre subintegração e sobreintegração: a cidadania inexistente. In: DADOS - Revista de Ciências Sociais, vol. 37, n. ${ }^{\circ}$ 2. Rio de Janeiro: IUPERJ, 1994.

NEVES, Marcelo. Entre Têmis e Leviatã: uma relação. São Paulo: Martins Fontes, 2012.

NEVES, Marcelo. La constituição y la esfera pública: entre diferenciación sistémica, inclusión y reconocimiento. Doxa, Cadernos de filosofia del derecho, [S.1.], n. 37, p. 180-183, 2014.

OLIVEIRA, Luciano. Do nunca mais ao eterno retorno: uma reflexão sobre a tortura. São Paulo: Brasiliense, 1994.

PIAGET, Jean. A formação do símbolo na criança: imitação, jogo e sonho, imagem e representação. $2^{\mathrm{a}}$. ed. Rio de Janeiro: Zahar, 1975.

SCHMITT, Carl. O Conceito do Político. Belo Horizonte: Del Rey, 2009. 